\title{
Preparation of ultrafine poly(sodium 4-styrenesulfonate) fibres via electrospinning
}

\author{
JIA XU*, XUEJUN CUI ${ }^{\dagger}$, HONGYAN WANG ${ }^{\dagger}$, JUNFENG LI $I^{\dagger}$ and SHIJIN DONG ${ }^{\dagger}$ \\ School of Chemistry and Environmental Engineering, Changchun University of Science and Technology, Changchun \\ 130022, P. R. China \\ ${ }^{\dagger}$ College of Chemistry, Jilin University, Changchun 130012, P. R. China
}

MS received 16 August 2010; revised 24 October 2010

\begin{abstract}
The ultrafine poly (sodium 4-styrenesulfonate) (NaPSS) fibres have been prepared for the first time by electrospinning. The spinning solutions (NaPSS aqueous solutions) in varied concentrations were studied for electrospinning into ultrafine fibres. The results indicated that the smooth fibre could be formed when the concentration of NaPSS was above $40 \mathrm{wt}$ \%. The morphology of the fibres was shown by scanning electron microscope (SEM). The Fourier transform infrared spectroscopy (FTIR) indicated that the structure of NaPSS did not change after electrospinning.
\end{abstract}

Keywords. NaPSS; ultrafine fibre; electrospinning; SEM; FTIR.

\section{Introduction}

The electrospinning technique has been proved to be a facile and effective method for manufacturing micro/nanoscale polymer fibres and polymer/inorganics composite fibres (Huang et al 2003; Xia et al 2003). The basic requirements for electrospinning are a polymer source, a high voltage supply, and a collector (Fong et al 1999). When a strong electrostatic force is applied to the capillary containing a polymer solution, the solution is ejected from the capillary and deposited as a nonwoven fibre mat on a collector serving as the ground for the electric charges (Lannutti et al 2007). The micro/nanofibres produced by electrospinning method have shown amazing characteristics such as very large surface area-to-volume ratio and high porosity with very small pore size (Park et al 2004). Many polymers have been spun into fibres by electrospinning (Kim et al 2005; Zhou et al 2006; Gupta et al 2005; Ohkawa et al 2004; Son et al 2005). However, as a typical polyelectrolyte, the electrospinning of sodium polystyrene sulfonate have never been reported.

In this study, the ultrafine NaPSS fibres were successfully prepared by electrospinning technique. The results were characterized by scanning electron microscope (SEM) and Fourier transform infrared spectroscopy (FTIR).

\footnotetext{
*Author for correspondence (xujia@ cust.edu.cn)
}

\section{Experimental}

\subsection{Materials}

Poly(sodium 4-styrenesulfonate) (NaPSS, Mw =100,000) was purchased from XZL Chemicals Co., Ltd (China). Distilled water was used as solvent.

\subsection{Instruments}

The scanning electron microscopy (SEM) measurements were recorded on a SHIMADZU SSX-550 microscope. FTIR spectra were recorded on a Nicolet Instruments Research series 5PC Fourier transform infrared spectrometer.

\subsection{Preparation of ultrafine NaPSS fibres}

The NaPSS aqueous solution of various concentrations (20, 29, 40 and 49 wt.\%) were collected and stirred for $6 \mathrm{~h}$ at room temperature. The electrospinning experiments were performed at room temperature. The polymer solution was placed into a $2 \mathrm{ml}$ glass syringe with a tip inner diameter of $1 \mathrm{~mm}$. A clamp connected with high voltage power supplier $(0$ $30 \mathrm{kV}$ ) was attached on the glass syringe. A piece of aluminum foil was placed towards the tip at a distance of $17 \mathrm{~cm}$ as grounded collector. The polymer jets generated from the tip by high voltage field to the grounded collector and formed the ultrafine fibre mesh. The apparatus for the electrospinning experiments was similar to previous report (Gupta et al 2005). 


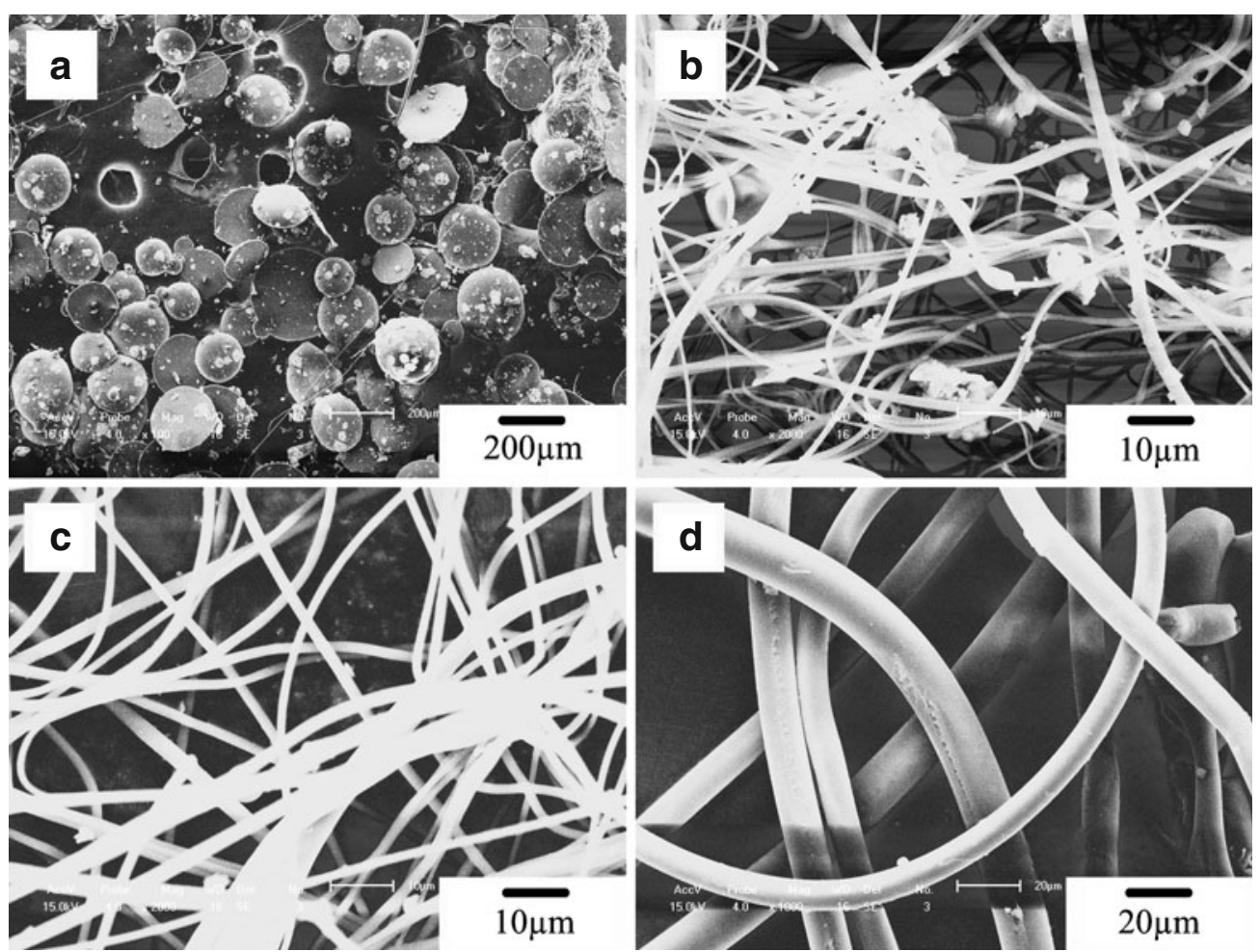

Figure 1. SEM images from NaPSS aqueous solution with various concentrations: (a) 20 wt.\%, (b) $30 \mathrm{wt} . \%$, (c) $40 \mathrm{wt} . \%$ and (d) $50 \mathrm{wt} . \%$.

\section{Results and discussion}

It could be seen that with the increment in the concentration of NaPSS solution, the results changed from spheres to fibres. When the concentration of NaPSS aqueous solution was $20 \mathrm{wt} . \%$, the electrospinning productions were almost microsphere structures with large diameters (figure 1a). When the concentration was $30 \mathrm{wt} . \%$, the electrospinning productions were fibres with many beads (figure 1b). Smooth fibre was formed when the NaPSS concentration was above 40 wt. $\%$. At 40 wt.\%, the diameter of the NaPSS fibres ranged from 1.3-3.5 $\mu \mathrm{m}$, with an average fibre diameter of $1.8 \mu$ (figure 1c). At $50 \mathrm{wt} . \%$, the viscosity of NaPSS solution was too high, so electrospinning process was fitful, and only a few large diameter fibres (above $9.5 \mu \mathrm{m}$ ) could be obtained on collector (figure 1d). Therefore, $40 \mathrm{wt} . \%$ was a suitable concentration for attaining the smooth fibres compared to those at other weight concentrations.

In order to examine whether the structure of NaPSS changed in the electrospinning process, IR spectra of both the raw material of NaPSS and the electrospun NaPSS were measured. Figure 2 shows IR spectra of the raw material (A) and electrospun fibres (B). Both of them had peaks of NaPSS at 1184,1130 and $1040 \mathrm{~cm}^{-1}$ (Yang et al 2002); where peaks at 1184 and $1040 \mathrm{~cm}^{-1}$ could be assigned to the $\mathrm{SO}^{3}$-group antisymmetric and symmetric vibrational adsorption peaks, respectively, and $1130 \mathrm{~cm}^{-1}$ to the in-plane skeleton vibration of benzene ring. It was concluded that the electrospinning process did not affect the structure of NaPSS.

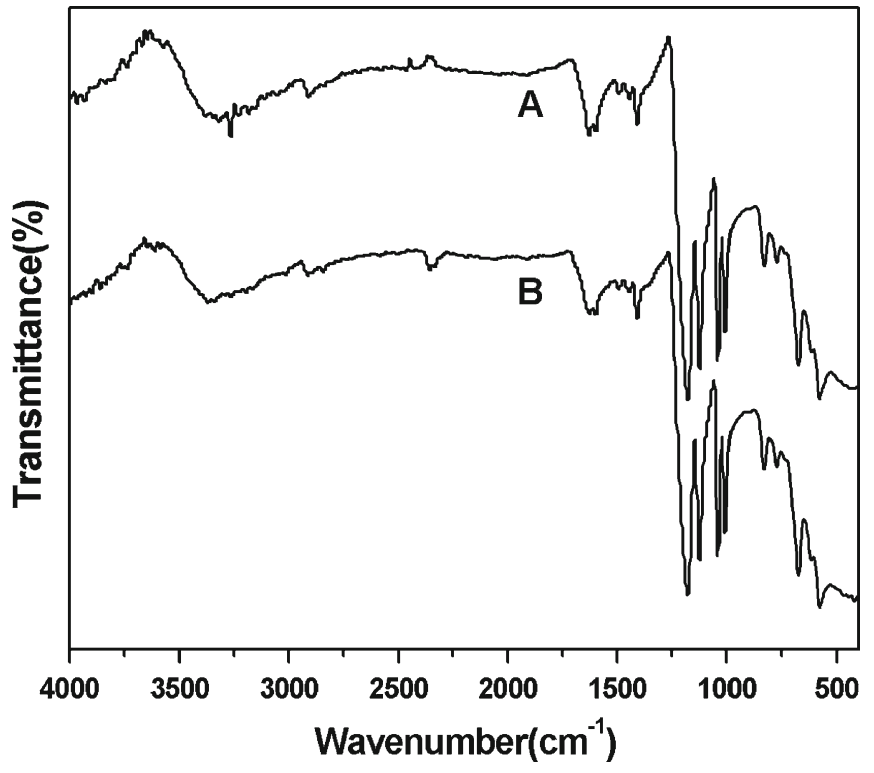

Figure 2. IR spectra of raw material of NaPSS (A) and electrospun NaPSS fibres (B).

\section{Conclusions}

The ultrafine NaPSS fibres have been successfully prepared by the electrospinning method. We found that water was a suitable solvent for the electrospinning of NaPSS fibres. With 
the increment in the concentration of the NaPSS solution, results changed from spheres to fibres. $40 \mathrm{wt} \%$ was a suitable concentration for attaining smooth fibres. The structure of NaPSS did not change in the electrospinning process.

\section{Acknowledgement}

The authors gratefully acknowledge the support of Bureau of Geological Survey of China (No.1212101660404).

\section{References}

Fong H, Chun I and Reneker D H 1999 Polymer 404585

Gupta P, Elkins C, Long T E and Wilkes G L 2005 Polymer 464799
Huang Z M, Zhang Y Z, Kotakic M and Ramakrishna S 2003 Compos. Sci. Technol. 632223

Kim B, Park H, Lee S H and Sigmund W M 2005 Mater. Lett. 59 829

Lannutti J, Reneker D, Ma T, Tomasko D and Farson D 2007 Mater. Sci. Eng. C27 504

Ohkawa K, Cha D, Kim H, Nishida A and Yamamoto H 2004 Macromol. Rapid Commun. 251600

Park W H, Jeong L, Yoo D I and Hudson S 2004 Polymer 45 7151

Son W K, Youk J H, Lee T S and Park W H 2005 Mater. Lett. 59 1571

Xia Y, Yang P, Sun Y, Wu Y, Mayers B, Gates B, Yin Y, Kim F and Yan H 2003 Adv. Mater. 15353

Yang J C, Jablonsky M J and Mays J W 2002 Polymer 435125

Zhou H J, Green T B and Joo Y L 2006 Polymer 477497 